\title{
Robust interval quadratic programming and its application to waste management under uncertainty
}

\author{
Yongping $\mathrm{Li}^{1 *}$ and Guohe Huang ${ }^{2}$
}

\begin{abstract}
Background: No country has ever experienced as large or as fast an increase in municipal solid waste (MSW) quantities that China is now facing. The MSW generation rate in the City of Changchun continues to increase since it has been encountered swift urbanization, industrialization and economic development during the past decades.

Results: In this study, a robust interval quadratic programming method is developed for the planning of MSW management in the City of Changchun, China. The developed method can not only tackle uncertainties expressed as interval values, fuzzy sets, and their combinations, but also reflect economies-of-scale effects on waste disposal of cost.

Conclusions: The results are valuable for helping governmental officials more intuitive to know some basic situation, such as optimal waste-flow allocation, waste-flow routing, facility-capacity expansion, and system cost over the planning horizon. Results can also be used to generate decisions for supporting the city's long-term MSW management and planning, and thus help managers to identify desired MSW management policies in association with cost minimization under uncertainty.
\end{abstract}

Keywords: Environment, Management, Fuzzy sets, Policy analysis, Quadratic programming, Solid waste, Uncertainty

\section{Background}

For decades, massive urbanization and rapid development of global urban economy have increased municipal solid waste (MSW) generation rate. MSW management is crucial for environmental protection and public health and has become a major challenge confronted by the world, particularly for many urban regions of developing countries. For example, global waste generation rate has nearly doubled since 1960, from 2.7 to 4.4 pounds per capital per day, while more than $70 \%$ of MSW generated is disposed of at landfills (USEPA, 2007). Due to the waste management hierarchy, one of the greatest challenges that decision makers face is to figure out how to diversify the treatment options, increase the reliability of infrastructure systems, and leverage the redistribution of waste streams among landfilling, incineration, compost, recycling and

\footnotetext{
* Correspondence: yongping.li@iseis.org

${ }^{1}$ MOE Key Laboratory of Regional Energy Systems Optimization, Resources and Environmental Research Academy, North China Electric Power University, Beijing 102206, China

Full list of author information is available at the end of the article
}

other facilities (Chang and Davila, 2007). Consequently, many urban regions and countries have established various kinds of laws and regulations to enhance MSW management and planning. A large number of optimization techniques have been proposed for supporting decisions of MSW management and evaluating relevant operation and investment policies; they involve linear, dynamic, integer and multiobjective programming methods (Baetz, 1990; Lund et al. 1994; Masui et al. 2000; Kollikkathara et al. 2010; Cao and Huang, 2011).

The complexity of planning MSW management can be significantly compounded by the fact that many system components cannot be known with certainty beforehand. Hence, in many real-world applications, the quality of information produced by deterministic optimization techniques can be rendered highly questionable when the input data cannot be expressed with precision ( $\mathrm{Li}$ and Huang, 2006; Li et al. 2011). The complexities could be further amplified not only by interactions among the uncertain parameters but also through additional economic implications. Such complexities have placed many MSW 
management problems beyond deterministic programming methods. Data imprecision can be addressed through optimization approaches such as fuzzy, stochastic and interval mathematical programming (Wilson and Baetz, 2001a, b; Huang et al. 2005a, b; El Hanandeh and El-Zein, 2010; Fan and Huang, 2012). Fuzzy mathematical programming considers uncertainties as fuzzy sets, and is effective in reflecting ambiguity and vagueness in resource availabilities. Robust programming based on the concept of fuzzy interval was able to deal with ambiguous coefficients in the optimization model and reflect the vague information of decision makers' implicit knowledge (Inuiguchi and Sakawa, 1998; Dubois et al. 2001; Ben-Tal and Nemirovski, 2002; Li et al. 2008). Moreover, this method delimits an uncertain decision space by specifying uncertainties through dimensional enlargement of the original fuzzy constraints, and thus enhances the robustness of the optimization process.

However, economies of scale (EOS) may affect the cost coefficients in a mathematical programming problem and make the relevant objective function nonlinear; difficulties arise due to system nonlinearities when these methods are applied to MSW management problems. Even if a nonlinear model was formulated, the modelers would prefer to convert it into equivalent linear forms and use linear methods for generating solutions (Ko and Chang, 2008; Li et al. 2009). Nonlinear mathematical models for realworld applications are hampered by a general lack of appropriate modeling solutions for effectively addressing uncertainties and nonlinearities simultaneously. Quadratic programming is useful for reflecting nonlinearity in cost objectives and has global optimum under a number of system conditions (Hillier and Lieberman 1986). Previously, a few studies incorporating uncertainty within MSW planning were reported, through introducing fuzzy and/or interval optimization methods into the quadratic programming framework to reflect uncertainty and nonlinearity (Chen and Huang, 2001). Fuzzy-based quadratic programming is incapable of dealing with ambiguous coefficients or decision makers' vague preferences; interval-based quadratic programming has difficulties in addressing uncertainties presented in terms of probabilistic or possibilistic distributions.

China has experienced a very rapid increase in its economy during the last two decades. However, in the absence of a comprehensively sustainable development scheme, this increase has brought severe environmental issues, such as water resources depletion and pollution, soil erosion, desertification, acid rain, sandstorms, forest depletion, and solid waste pollution. Among them, solid waste is becoming a critical issue, not only in terms of the impacts being created but also in terms of resources being consumed. No country has ever experienced as large or as fast an increase in solid waste quantities that
China is now facing. China produces around 29\% of the world's solid waste each year, and with the economy continuing to grow rapidly, it is clear that China bears what may be the heaviest solid waste management burden in the world. It has been estimated that the amounts of industrial waste increased by $10 \%$ while at the same time municipal waste increased by $15 \%$ per year in China. In 2004, China surpassed the United States becoming as the world's largest waste generator, and by 2030 China's annual solid waste quantities will increase by another $150 \%$ - growing from about 190 million tons in 2004 to over 480 million tons in 2030 ( $\mathrm{Su}$ et al. 2009). Therefore, development of systems analysis method for effective managing MSW and thus providing scientific bases for decision makers is desired.

The objective of this study is to develop a robust interval quadratic programming method for the planning of MSW management in the City of Changchun, China. Robust programming method will be incorporated within an interval quadratic programming framework for better accounting for uncertainties and nonlinearities. The developed method will then be applied to a case of long-term waste management planning. It can not only handle uncertainties expressed as fuzzy sets and interval values, but also deal with nonlinearities in the objective function to reflect the effect of EOS on waste management cost. The results can be used for generating a range of decision alternatives under various system conditions, and thus helping managers to identify desired waste-management policies.

\section{Methods}

Interval programming is a technique that readily processes interval data, thereby avoiding many problems encountered by other optimization methods (e.g. stochastic programming) when faced with parameter uncertainty. Since practitioners generally find it easier to specify estimates of fluctuation ranges than to determine appropriate distributional information, interval value proves especially meaningful in most practical settings. Consider an interval quadratic programming problem without $x_{j} x_{k}(j \neq k)$ terms as follows (Chen and Huang, 2001):

$$
\operatorname{Min} f^{ \pm}=\sum_{j=1}^{n}\left[c_{j}^{ \pm} x_{j}^{ \pm}+d_{j}^{ \pm}\left(x_{j}^{ \pm}\right)^{2}\right]
$$

subject to:

$$
\begin{aligned}
& \sum_{j=1}^{n} a_{i j}^{ \pm} x_{j}^{ \pm} \leq b_{j}^{ \pm}, \quad i=1,2, \ldots, m \\
& x_{j}^{ \pm} \geq 0, j=1,2, \ldots, n
\end{aligned}
$$
where $a_{i j}^{ \pm}, b_{i}^{ \pm}, c_{j}^{ \pm}, d_{j}^{ \pm}$and $x_{j}^{ \pm}$are interval parameters/variables; the '-' and ' + ' superscripts represent lower and upper bounds of an interval parameter/variable, respectively. If the quadratic programming problem satisfies the Kuhn-Tucker 
conditions (Kuhn and Tucker, 1951) or has a concave objective function, it will then have a global optimum. Such a problem can then be transformed into two deterministic submodels that correspond to lower and upper bounds of the objective-function value, based on an interactive algorithm (Chen and Huang, 2001). However, model (1) has difficulties in reflecting uncertainties presented as fuzzy sets; moreover, it may lead to infeasibility when the model's righthand-side parameters have large intervals.

Robust programming involves the optimization of a precise objective function subject to a fuzzy decision space delimited by constraints with fuzzy coefficients and fuzzy capacities (Inuiguchi and Sakawa, 1998). By delimiting the uncertain decision space through dimensional enlargement of the original fuzzy constraints, this approach can enhance the robustness of the optimization effort. A general robust programming problem can be defined as follows:

Min $f=C X$

subject to:

$$
\begin{aligned}
& A X \underset{\sim}{ }=8 \\
& X \geq 0
\end{aligned}
$$

where $\mathrm{A} \in\{\mathfrak{R}\}^{\mathrm{m} \times \mathrm{n}}, \mathrm{B} \in\{\mathfrak{R}\}^{\mathrm{m} \times 1}, \mathrm{C} \in\{\mathrm{R}\}^{1 \times \mathrm{n}}, \mathrm{X} \in\{\mathrm{R}\}^{\mathrm{n} \times 1}$, $\mathfrak{R}$ denotes a set of fuzzy parameters and variables, $\mathrm{R}$ denotes a set of deterministic numbers, and $\leqq$ means fuzzy inequality. Let constraints in (2b) take the following specific form:

$$
A_{1} x_{1} \oplus A_{2} x_{2} \oplus \cdots \oplus A_{n} x_{n} \leq \underset{\sim}{B}
$$

where $A_{j}(j=1,2, \ldots, n)$ and $B$ are fuzzy subsets, and symbol $\oplus$ denotes addition of fuzzy subsets. Fuzziness of the decision space is due to uncertainties in coefficients $A_{j}$ and $B$. Letting $\underset{\sim}{\underset{j}{U}}$ and $\underset{\sim}{V}$ be base variables imposed by fuzzy subsets $A_{j}$ and $B$, we have:

$$
\begin{array}{ll}
\mu_{A j}: & U_{\sim}-[\mathbf{0}, \mathbf{1}] \\
\mu_{B}: & V_{\sim}-[\mathbf{0}, \mathbf{1}]
\end{array}
$$

where $\mu_{A j}$ denotes the possibility of consuming a specific amount of resource by activity $j$, and $\mu_{B}$ indicates the possible availability of resource $B$. Fuzzy subset $N$ can be expressed as the following L-R fuzzy numbers (Dubois and Prade, 1978):

$$
\mu_{N}(x)= \begin{cases}F_{L}\left(\frac{u-x}{\beta}\right), & \text { if }-\infty<x<u, \beta>0 \\ 1, & \text { if } x=u \\ F_{R}\left(\frac{x-u}{\delta}\right), & \text { if } u<x<+\infty, \delta>0\end{cases}
$$

where $u$ is the mean value of $N ; \beta$ and $\delta$ are the left and right spreads, respectively; $F_{L}$ and $F_{R}$ are the shape functions. For a linear case, fuzzy subset $N$ can be defined as follows:

$$
\mu_{N}(x)=\left\{\begin{array}{lr}
0, & \text { if } x<\underline{a} \text { or } x>\bar{a} \\
1, & \text { if } x=u \\
1-2|u-x| /(\bar{a}-\underline{a}), & \text { if } \underline{a} \leq x \leq \bar{a}
\end{array}\right.
$$

where $[\underline{a}, \bar{a}]$ is an interval imposed by fuzzy subset $N$. According to the concept of level set (fuzzy $\alpha$-cut) and the representation theorem, constraints in (3) can be represented as follows:

$$
\left.(\underset{\sim}{A})_{\alpha} x_{1} \oplus(\underset{\sim}{A})_{\alpha} x_{2} \oplus \cdots \oplus \underset{\sim}{\left(A_{n}\right.}\right)_{\alpha} x_{n} \subseteq \underset{\sim}{B}, \alpha \in[0,1]
$$

where

$$
\begin{aligned}
& \left(\underset{\sim}{A_{j}}\right)_{\alpha}=\left\{a_{j} \in \underset{\sim}{U_{j}} \mid \mu_{A_{j}}\left(a_{j}\right) \geq \alpha\right\} \\
& {\underset{\sim}{\alpha} \alpha}_{\alpha}=\left\{b \in \underset{\sim}{V} \mid \mu_{B}(b) \geq \alpha\right\}
\end{aligned}
$$

Assume that the fuzzy subsets in Equation (3) are finite and have the following characteristic:

$$
\left\{\mu_{A_{j}}\left(a_{j}\right) \mid a_{j} \in \underset{\sim}{U_{j}}\right\}=\left\{\alpha_{1}, \alpha_{2}, \cdots, \alpha_{k}\right\}
$$

where $0 \leq \alpha_{1} \leq \alpha_{2} \leq \ldots \leq \alpha_{\mathrm{k}} \leq 1$. Then, for each $\alpha_{s}(s=1,2$, ..., $k$ ), constraints in (6a) become:

$$
\left({ }_{\sim}{ }_{1}\right)_{\alpha_{s}} x_{1} \oplus(\underset{\sim}{A})_{\alpha_{s}} x_{2} \oplus \cdots \oplus(\underset{\sim}{A})_{\alpha_{s}} x_{n} \subseteq \underset{\sim}{B}{ }_{\alpha_{s}}, \alpha_{s} \in[0,1]
$$

where $(\underset{\sim}{A} j)_{\alpha_{s}}(j=1,2, \ldots, n ; s=1,2, \ldots, k)$ and $\underset{\sim}{B} \alpha_{s}$ constitute convex and non-empty fuzzy sets. Then, fuzzy constraints in (8) can be replaced by the following $2 k$ precise inequalities, where $k$ denotes the number of $\alpha$-cut levels (Luhandjula and Gupta, 1996):

$$
\begin{aligned}
& \bar{a}_{1}^{s} x_{1}+\bar{a}_{2}^{s} x_{2}+\cdots+\bar{a}_{n}^{s} x_{n} \leq \bar{b}^{s}, s=1,2, \ldots, k \\
& \underline{a}_{1}^{s} x_{1}+\underline{a}_{2}^{s} x_{2}+\cdots, s=1,2, \ldots, k+\underline{a}_{n}^{s} x_{n} \geq \underline{b}^{s}
\end{aligned}
$$

with

$$
\begin{aligned}
& \bar{a}_{j}^{s}=\sup \left(a_{j}^{s}\right), a_{j}^{s} \in(\underset{\sim}{A})_{\alpha_{s}} \\
& \underline{a}_{j}^{s}=\inf \left(a_{j}^{s}\right), a_{j}^{s} \in(\underset{\sim}{A})_{\alpha_{s}} \\
& \bar{b}^{s}=\sup \left(b^{s}\right), b^{s} \in{\underset{\sim}{a_{s}}}_{a_{s}} \\
& \underline{b}^{s}=\inf \left(b^{s}\right) b^{s} \in{\underset{\sim}{a_{s}}}_{a_{s}}
\end{aligned}
$$

where $\sup (t)$ and $\inf (t)$ denote the superior and inferior limits among set $t$, respectively. Therefore, for a fuzzy 
robust linear program with $m$ fuzzy constraints, the decision space for problem (2b) can be delimited by the following deterministic constraints based on the relations as defined in (6a) to (9f):

$$
\begin{aligned}
& \sum_{j=1}^{n}\left(\bar{a}_{i j}^{s} x_{j}\right) \leq \bar{b}_{i}^{s}, i=1,2, \ldots, m ; s=1,2, \ldots, k \\
& \sum_{j=1}^{n}\left(\underline{a}_{i j}^{s} x_{j}\right) \geq \underline{b}_{i}^{s}, i=1,2, \ldots, m ; s=1,2, \ldots, k \\
& x_{j} \geq 0, j=1,2, \ldots, n
\end{aligned}
$$

Obviously, the robust programming model can be converted into a deterministic version through transforming the $m$ imprecise constraints into $2 \mathrm{~km}$ precise inclusive ones that correspond to $k \alpha$-cut levels, such that robustness of the optimization process could be enhanced (Li et al. 2008). However, the robust programming method may become inapplicable when uncertainties and nonlinearities exist in the objective function; besides, it has difficulties in dealing with uncertainties that cannot be presented as membership functions. Therefore, robust programming will be incorporated within an interval quadratic programming framework in response to the above challenges. This leads to a robust interval quadratic programming model as follows:

$$
\operatorname{Min} f^{ \pm}=\sum_{j=1}^{n}\left[c_{j}^{ \pm} x_{j}^{ \pm}+d_{j}^{ \pm}\left(x_{j}^{ \pm}\right)^{2}\right]
$$

subject to:

$$
\begin{aligned}
& \sum_{j=1}^{n} a_{r j}^{ \pm} x_{j}^{ \pm} \leq b_{r}^{ \pm}, r=1,2, \ldots, m_{1} \\
& \sum_{j=1}^{n} a_{\sim t j}^{ \pm} x_{j}^{ \pm} \sim_{\sim}^{\sim} b_{t}^{ \pm}, t=m_{1}+1, m_{1}+2, \ldots, m \\
& x_{j}^{ \pm} \geq 0, j=1,2, \ldots, n
\end{aligned}
$$

where $\underset{\sim}{a} \pm$ and $b_{\tau}^{ \pm}$denote a set of intervals with vague lower and upper bounds. Assume that no intersection exists between the fuzzy sets at the two bounds. Letting $\underset{\sim}{a} a_{j}^{-}$and $\underset{\sim}{a}+j$ be lower and upper bounds of $\underset{\sim}{a}$, we have $\underset{\sim}{a t j}=\left[\begin{array}{ll}a_{t j}^{-} & a_{\sim j}^{+}\end{array}\right]$.

Since nonlinearity exists in the objective function, it is difficult in defining the bounds for cost coefficients and decision variables corresponding to $f^{-}$and $f^{+}$. Consequently, two situations need to be considered. When cost coefficients $c_{j}^{ \pm}$and $d_{j}^{ \pm}$have different signs (i.e. when $c_{j}^{ \pm} \geq 0$, then $d_{j}^{ \pm}$would be $\leq 0$, and vice versa), the optimal bound distribution for $x_{j}^{ \pm}$can be identified based on a derivative algorithm proposed by Chen and Huang
(2001). Firstly, let all left- and/or right-hand-side coefficients be equal to their mid-values. Then, model (11) can be converted into a robust deterministic quadratic programming problem as follows:

$$
\operatorname{Min} f_{\mathrm{mv}}=\sum_{j=1}^{n}\left[\left(c_{j}\right)_{\mathrm{mv}}\left(x_{j}\right)_{\mathrm{mv}}+\left(d_{j}\right)_{\mathrm{mv}}\left(x_{j}\right)_{\mathrm{mv}}^{2}\right]
$$

subject to:

$$
\begin{aligned}
& \sum_{j=1}^{n}\left(a_{r j}\right)_{\mathrm{mv}}\left(x_{j}\right)_{\mathrm{mv}} \leq\left(b_{r}\right)_{\mathrm{mv}}, \forall r \\
& \sum_{j=1}^{n}\left(\bar{a}_{t j}^{s}\right)_{\mathrm{mv}}\left(x_{j}\right)_{\mathrm{mv}} \leq\left(\bar{b}_{t}^{s}\right)_{\mathrm{mv}}, \forall t ; s=1,2, \cdots, k \\
& \sum_{j=1}^{n}\left(\underline{a}_{t j}^{s}\right)_{\mathrm{mv}}\left(x_{j}\right)_{\mathrm{mv}} \geq\left(\underline{b}_{t}^{s}\right)_{\mathrm{mv}}, \forall t ; s=1,2, \cdots, k \\
& \left(x_{j}\right)_{\mathrm{mv}} \geq 0, j=1,2, \ldots, n
\end{aligned}
$$

where $\left(c_{j}\right)_{\mathrm{mv}},\left(d_{j}\right)_{\mathrm{mv}},\left(a_{r j}\right)_{\mathrm{mv}}$ and $\left(b_{r}\right)_{\mathrm{mv}}$ are mid-values of $c_{j}^{ \pm}$, $d_{j}^{ \pm}, a_{r j}^{ \pm}$and $b_{r}^{ \pm}$[e.g. $\left(c_{j}\right)_{\mathrm{mv}}=\left(c_{j}^{-}+c_{j}^{+}\right) / 2$ ]; $\left(\underline{a}_{t j}^{s}\right)_{\mathrm{mv}}$, $\left(\bar{a}_{t j}^{s}\right)_{\mathrm{mv}},\left(\underline{b}_{t}^{s}\right)_{\mathrm{mv}}$ and $\left(\bar{b}_{t}^{s}\right)_{\mathrm{mv}}$ are mid-values of $a_{\sim j}^{ \pm}$and $\underline{\sim}_{i}^{ \pm}$[e.g. $\left.\left(\underline{a}_{t j}^{s}\right)_{\mathrm{mv}}=\left(\underline{a}_{t j}^{-s}+\underline{a}_{t j}^{+s}\right) / 2\right]$. The solutions for model (12) are $X_{\mathrm{mv} \mathrm{opt}}=\left\{\left(x_{j}\right)_{\mathrm{mv} \text { opt }} \mid \forall j\right\}$, where $\left(x_{j}\right)_{\mathrm{mv} \mathrm{opt}} \in\left[x_{j \mathrm{opt}}^{-}, x_{j \mathrm{opt}}^{+}\right], \forall j$.

Secondly, the optimal bound distribution for $x_{j}^{ \pm}$can be identified according to the following criteria:

$$
\begin{array}{r}
f_{j}^{+}\left(x_{j \mathrm{opt}}^{+}\right) \geq f_{j}^{+}\left(x_{j \mathrm{opt}}^{-}\right), \text {when } 2 d_{j}^{+}\left(x_{j}\right)_{\mathrm{mv} \mathrm{opt}}+c_{j}^{+}>0 \\
(13 \mathrm{a}) \\
f_{j}^{+}\left(x_{j \mathrm{opt}}^{+}\right) \leq f_{j}^{+}\left(x_{j \mathrm{opt}}^{-}\right), \text {when } 2 d_{j}^{+}\left(x_{j}\right)_{\mathrm{mv} \mathrm{opt}}+c_{j}^{+}<0
\end{array}
$$

When criterion (13a) is satisfied, then $x_{j}^{+}$corresponds to $f^{+}$; when criterion (13b) holds, then $x_{j}^{-}$corresponds to $f^{+}$. Assume criterion (13a) is satisfied, we can convert model (11) into two submodels (corresponding to $f^{-}$and $f^{+}$) as follows: 


\section{Submodel (1)}

$$
\begin{aligned}
\operatorname{Min} f^{-}= & \sum_{j=1}^{k_{1}}\left[c_{j}^{-} x_{j}^{-}+d_{j}^{-}\left(x_{j}^{-}\right)^{2}\right] \\
& +\sum_{j=k_{1}+1}^{n}\left[c_{j}^{-} x_{j}^{+}+d_{j}^{-}\left(x_{j}^{+}\right)^{2}\right]
\end{aligned}
$$

subject to:

$$
\sum_{j=1}^{k_{1}}\left|a_{r j}\right|^{+} \operatorname{Sign}\left(a_{r j}^{+}\right) x_{j}^{-}+\sum_{j=k_{1}+1}^{n}\left|a_{r j}\right|^{-} \operatorname{Sign}\left(a_{r j}^{-}\right) x_{j}^{+} \leq b_{r}^{-}, \forall r
$$

$$
\begin{gathered}
\left.\sum_{j=1}^{k_{1}} \overline{\left\{\left|a_{t j}\right|^{+} \operatorname{Sign}\left(a_{t j}^{+}\right)\right\}} x_{j}^{-}+\sum_{j=k_{1}+1}^{n} \frac{}{\left\{\left|a_{t j}\right|^{-} \operatorname{Sign}\left(a_{t j}^{-}\right)\right.}\right\}^{s} x_{j}^{+} \leq{\overline{b_{t}^{-}}}^{s}, \\
\forall t ; s=1,2, \cdots, k
\end{gathered}
$$

$$
\sum_{j=1}^{k_{1}} \frac{\left\{\left|a_{t j}\right|^{+} \operatorname{Sign}\left(a_{t j}^{+}\right)\right\}^{s} x_{j}^{-}+\sum_{j=k_{1}+1}^{n} \frac{\left\{\left|a_{t j}\right|^{-} \operatorname{Sign}\left(a_{t j}^{-}\right)\right\}}{{ }^{s}} x_{j}^{+} \geq \underline{b_{t}^{-s}},}{\forall t ; s=1,2, \cdots, k}
$$

$$
\begin{aligned}
& 0 \leq x_{j}^{-} \leq\left(x_{j}\right)_{\mathrm{mv} \mathrm{opt}}, j=1,2, \cdots, k_{1} \\
& x_{j}^{+} \geq\left(x_{j}\right)_{\mathrm{mv} \mathrm{opt}}, j=k_{1}+1, k_{1}+2, \cdots, n
\end{aligned}
$$

\section{Submodel (2)}

$$
\begin{aligned}
\operatorname{Min} f^{+}= & \sum_{j=1}^{k_{1}}\left[c_{j}^{+} x_{j}^{+}+d_{j}^{+}\left(x_{j}^{+}\right)^{2}\right] \\
& +\sum_{j=k_{1}+1}^{n}\left[c_{j}^{+} x_{j}^{-}+d_{j}^{+}\left(x_{j}^{-}\right)^{2}\right]
\end{aligned}
$$

subject to:

$$
\sum_{j=1}^{k_{1}}\left|a_{r j}\right|^{-} \operatorname{Sign}\left(a_{r j}^{-}\right) x_{j}^{+}+\sum_{j=k_{1}+1}^{n}\left|a_{r j}\right|^{+} \operatorname{Sign}\left(a_{r j}^{+}\right) x_{j}^{-} \leq b_{r}^{+}, \forall r
$$

$$
\begin{gathered}
\left.\sum_{j=1}^{k_{1}} \overline{\left\{\left|a_{t j}\right|^{-} \operatorname{Sign}\left(a_{t j}^{-}\right)\right.}\right\}^{s} x_{j}^{+}+\sum_{j=k_{1}+1}^{n} \frac{\left.\overline{\left\{\left|a_{t j}\right|^{+} \operatorname{Sign}\left(a_{t j}^{+}\right)\right.}\right\}^{s} x_{j}^{-} \leq{\overline{b_{t}^{+}}}^{s},}{\forall t ; s=1,2, \cdots, k}
\end{gathered}
$$

$$
\begin{gathered}
\sum_{j=1}^{k_{1}} \underline{\left\{\left|a_{t j}\right|^{-} \operatorname{Sign}\left(a_{t j}^{-}\right)\right\}^{s}} x_{j}^{+}+\sum_{j=k_{1}+1}^{n} \frac{\left\{\left|a_{t j}\right|^{+} \operatorname{Sign}\left(a_{t j}^{+}\right)\right\}^{s}}{x_{j}^{-} \geq \underline{b_{t}^{+s}},} \\
\forall t ; s=1,2, \cdots, k
\end{gathered}
$$

$$
\begin{aligned}
& x_{j}^{+} \geq\left(x_{j}\right)_{\mathrm{mv} \mathrm{opt}}, j=1,2, \cdots, k_{1} \\
& 0 \leq x_{j}^{-} \leq\left(x_{j}\right)_{\mathrm{mv} \mathrm{opt}}, j=k_{1}+1, k_{1}+2, \cdots, n
\end{aligned}
$$

Solving the above two submodels, we can obtain the solutions for model (11): $x_{j \mathrm{opt}}^{ \pm}=\left[x_{j \mathrm{opt}}^{-}, x_{j \mathrm{opt}}^{+}\right], \forall j$ and $f_{\mathrm{opt}}^{ \pm}=\left[f_{\mathrm{opt}}^{-}, f_{\mathrm{opt}}^{+}\right]$. When cost coefficients $c_{j}^{ \pm}$and $d_{j}^{ \pm}$have the same sign (i.e., when $c_{j}^{ \pm} \geq 0$, then $d_{j}^{ \pm} \geq 0$, and vice versa), model (11) can be directly transformed into two submodels, which correspond to the lower and upper bounds of the objective function value, respectively. Then, each submodel can be converted into a conventional linear program, provided that condition (7) is satisfied for each fuzzy constraint.

\section{Case study}

The case study will focus on the planning of waste-flow allocation and waste-management facility development/ expansion for the City of Changchun, which is the capital of Jilin Province and located in the northeast of China. The region covers an area of approximately 379.9 square kilometers, including five main districts (abbreviated as D1 to D5, as shown in Figure 1). The city has a population of 2.78 million, where the households generate residential wastes of approximately 3060 tonnes per day. The city's MSW collection and disposal system consists of six transfer stations, one waste-to-energy facility (i.e. Xinghua incinerator), and one landfill. Each district is responsible for its own curbside garbage collection, using either its own force or a contracted service. The city is responsible for the disposal of the collected wastes through the use of the transfer stations and waste management facilities. The majority of wastes collected through curbside pick-up from districts are delivered to the transfer stations, where some recyclable wastes received are recycled; then the others are compacted and hauled to the landfill or incinerator. The current operating capacities of transfer stations are approximately 2200 tonnes per day, less than the amount of waste generated. This leads to some wastes 


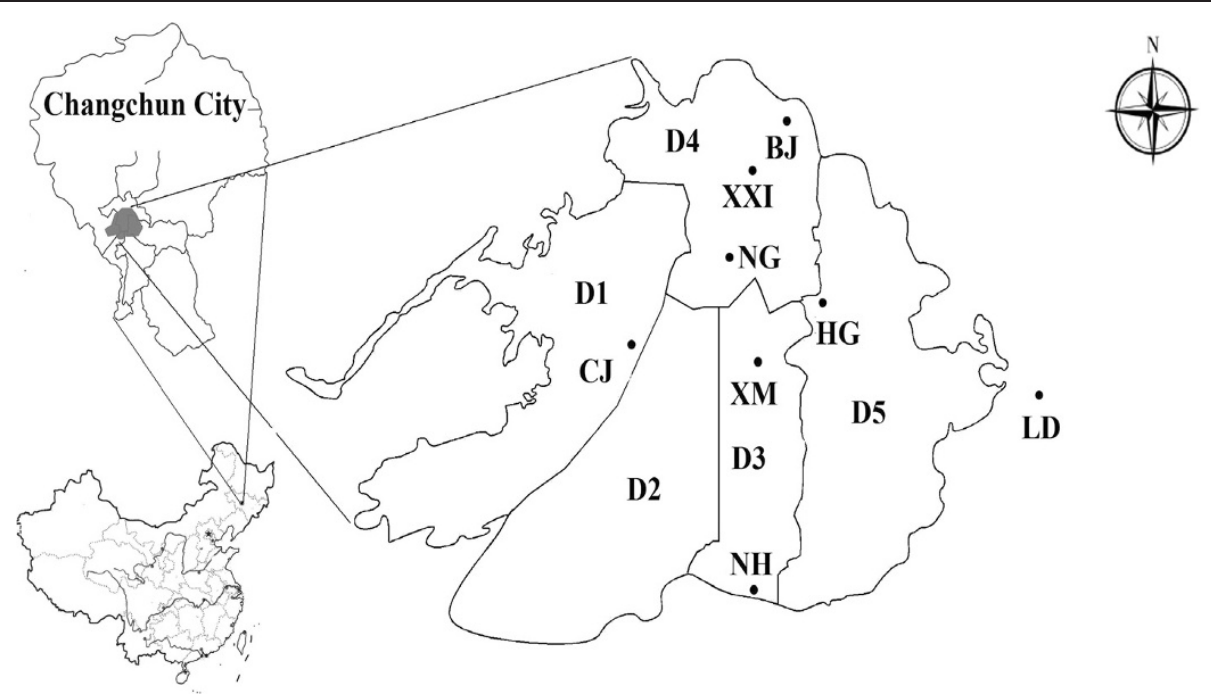

Figure 1 The study system (Symbols of “D1, D2, D3, D4 and D5" denote “Lvyuan, Chaoyang, Nanguan, Kuangcheng and Erdao districts, respectively; "LD" means landfill; "XXI" denotes "Xinxiang Incinerator"; "BJ, NG, CJ, XM, HG and NH" denote "transfer stations $1,2,3,4,5$ and 6", respectively).

directly being hauled to the landfill or the incinerator. Figure 2 shows the routine of waste allocation and disposal of. Source reduction and recycling are the two most desirable operations to achieve waste minimization (Tai et al. 2011); therefore, collecting recyclables at the source by residents. This minimization of total waste could benefit the stages of transportation and treatment. However, the quantity of recyclables collected by residents and junkmen greatly exceeds the quantity of recyclables in the municipal recycling system.

The MSW generated typically include paper, yard waste, food waste, plastics, metals, glass, wood and other items. Similar to many other cities in China, the study city mainly relies on the use of landfill for handling its solid waste. The landfill is used directly to satisfy waste

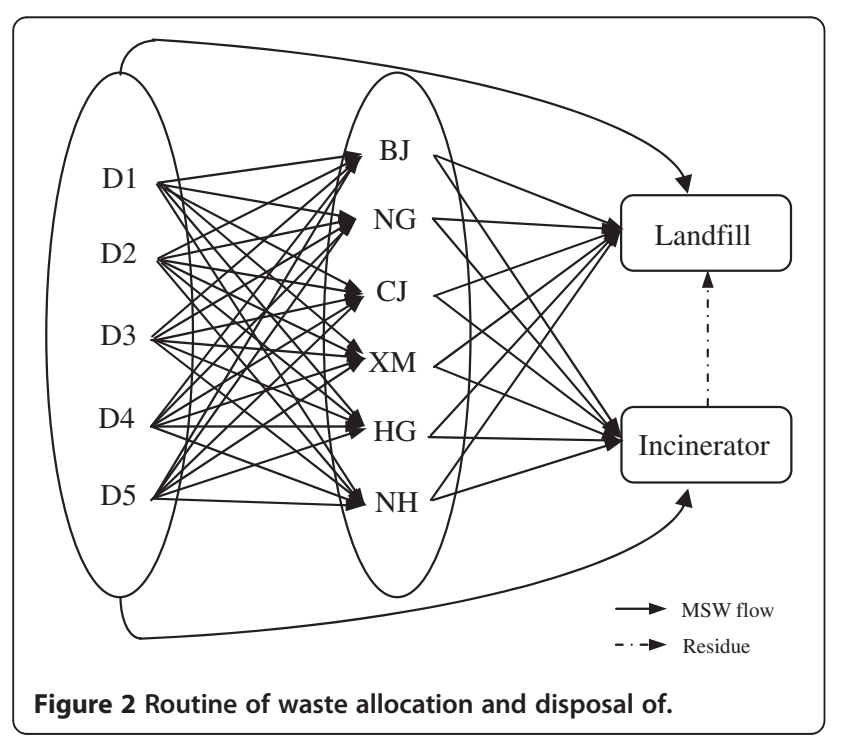

disposal demand or alternatively to provide capacity for the other facilities' residue disposals. Before 2008, approximately 2800 to 3000 tonnes per day of the waste (i.e. over $90 \%$ of total residential wastes) were buried at the landfill with simple pretreatment, especially in the areas of rural-urban fringe and countryside. In addition, the amount of residential waste diverted from landfill is still low (i.e. less than $17 \%$ of total wastes generated by households); increasing the waste diversion, separation and recovery rate and thus reducing the wastes to landfill are becoming an important goal. In 2009, the city built a waste-to-energy facility with a daily capacity of about 500 tonnes (i.e. the Xinxiang incinerator) to help reduce the amount of wastes that ends up at the landfill. The incinerator can generate approximately 51 million kwh per year and gain profits through the sale of electricity and environmentally-friendly building materials. Over the last ten years, the city has achieved significant improvements in waste management. Regional policies and guidelines for collection, transport, treatment and disposal of municipal and industrial wastes in environmentally safe ways have been established. However, the city has been unable to keep up with the growing demand for waste service coverage, environmental requirements for safe disposal systems, and rationalization of cost-effectiveness in service delivery. The capacities of waste management at regional and central levels, the abilities of the local scientists and technicians, and the environmental protection consciousness of the local communities are required to improve immediately to meet the requirements of environmental protection and regional sustainability.

Precise data is hard to be obtained due to temporal and spatial variations in MSW system conditions. The 
city's future MSW generation rate is uncertain since the city has been encountered rapid increase in the amount of MSW as a result of swift urbanization, industrialization and economic development during the past decades. The average waste-generation rate estimated may keep increasing to $1.30 \mathrm{~kg} / \mathrm{capita} /$ day in 2020 , while the city's population growth rate is $0.8 \%$ per year (CUPC, 2004); correspondingly, in 2020, the residential sector could generate around 4000 tonnes of wastes per day. This tendency could result in insufficient capacities of wastemanagement facilities to meet the overall waste disposal demand. Also, intrinsic fluctuations of many impact factors, such as waste compositions and operation conditions, may result in uncertainties associated with the capacities of waste management facilities. Waste collection cost can also be affected by vehicle types, collection efficiencies, oil prices, and collection routes; the operation cost may be related to labor fees, equipment prices, energy prices, and management expenses; these can result in uncertainties in estimating the costs for waste collection, transportation and disposal of. For example, collection cost within a collection area depends on the type of vehicle used (and costs associated with it) and the efficiency of collection. The efficiency of collection in turn depends on factors such as type of vehicle, crew size, collection routes, collection frequency, and local conditions. The waste transportation cost is related to vehicle movements outside the collection areas during a working day. Consequently, interactions exist among the waste flows and their transportation costs; particularly, when waste flows are high or hauling distances are long, the effects of EOS may become significant. In general, the EOS effects in terms of waste transportation/operation can be expressed as a sizing model with a power law (Thuesen et al. 1977):

$$
C_{t}=C_{r e}\left(X_{t} / X_{r e}\right)^{m}
$$

where $X_{t}$ is decision variable for waste flow (tonne/day), $X_{r e}$ is a reference waste flow (tonne/day), $C_{t}$ is the transportation/treatment cost for waste flow $X_{t}$ (\$/tonne), $C_{r e}$ is a known cost for reference waste flow $X_{r e}(\$ /$ tonne), and $m$ is an EOS exponent $(0<m<1)$.

Table 1 presents waste-generation rates for the five districts. The study time span is 15 years, which is further divided into three 5 -year periods. Tables 2 and 3 show transportation costs for waste flows from districts to transfer stations, districts to landfill/incinerator, and transfer stations to landfill/incinerator. The nonlinear relationships in transportation cost were approximated by inexact linear functions. In this study, the EOS exponent for transportation cost is $0.8 \sim 0.9$. Figure 3 shows the curve of waste flow vs transportation cost from district 1 to landfill in period 1. Table 4 shows the other modeling inputs,
Table 1 Waste-generation rate

\begin{tabular}{llll}
\hline District & $\mathbf{k = 1}$ & $\mathbf{k = 2}$ & $\mathbf{k = 3}$ \\
\hline D1 & {$[590,670]$} & {$[610,700]$} & {$[638,722]$} \\
D2 & {$[765,870]$} & {$[795,907]$} & {$[825,941]$} \\
D3 & {$[630,719]$} & {$[656,747]$} & {$[683,776]$} \\
D4 & {$[486,552]$} & {$[511,574]$} & {$[526,597]$} \\
D5 & {$[403,457]$} & {$[419,476]$} & {$[436,494]$} \\
\hline
\end{tabular}

implying that a variety of uncertainties presented as different formats (e.g. deterministic and fuzzy intervals) exist in the modeling parameters.

In general, uncertainties and nonlinearities exist in the city's MSW management activities, which can affect the optimization processes and the decision schemes generated. Therefore, based on the robust interval quadratic programming method, the study problem can be formulated as follows:

$$
\begin{aligned}
\text { Min } f^{ \pm} & =\sum_{i=1}^{2} \sum_{j=1}^{5} \sum_{k=1}^{3} L_{k} X_{i j k}^{ \pm}\left[\left(\alpha_{i j k}^{ \pm} X_{i j k}^{ \pm}+\beta_{i j k}^{ \pm}\right)+O P_{i k}^{ \pm}\right] \\
& +\sum_{r=1}^{6} \sum_{j=1}^{5} \sum_{k=1}^{3} L_{k} X_{r j k}^{ \pm}\left[\left(\alpha_{r j k}^{ \pm} X_{r j k}^{ \pm}+\beta_{r j k}^{ \pm}\right)+O P_{r k}^{ \pm}\right] \\
& +\sum_{i=1}^{2} \sum_{r=1}^{6} \sum_{k=1}^{3} L_{k} X_{i r k}^{ \pm}\left[\left(\alpha_{i r k}^{ \pm} X_{i r k}^{ \pm}+\beta_{i r k}^{ \pm}\right)+O P_{i k}^{ \pm}\right] \\
& +\sum_{k=1}^{3} L_{k}\left\{\left(\sum_{j=1}^{5} F E_{1}^{ \pm} X_{2 j k}^{ \pm}+\sum_{r=1}^{6} F E_{2}^{ \pm} X_{2 r k}^{ \pm}\right)\right. \\
& \left.\quad+O \alpha_{2 k}^{ \pm}\left(\sum_{j=1}^{5} F E_{1}^{ \pm} X_{2 j k}^{ \pm}+\sum_{r=1}^{6} F E_{2}^{ \pm} X_{2 r k}^{ \pm}\right)+\beta_{2 k}^{ \pm}\right] \\
& -\sum_{k=1}^{3} L_{k} R E_{2 k}^{ \pm}\left(\sum_{j=1}^{5} \eta_{1}^{ \pm} X_{2 j k}^{ \pm}+\sum_{r=1}^{6} \eta_{2}^{ \pm} X_{2 r k}^{ \pm}\right) \\
& -\sum_{j=1}^{5} \sum_{r=1}^{6} L_{k} R E_{r k}^{ \pm} \eta_{3}^{ \pm} X_{r j k}^{ \pm}+\sum_{r=1}^{6} \sum_{k=1}^{3} V T C_{r k}^{ \pm} \cdot E T C_{r k}^{ \pm} \\
& +\sum_{k=1}^{3} V L C^{ \pm} \cdot E L C^{ \pm}+\sum_{k=1}^{3} V I C_{k}^{ \pm} \cdot E I C_{k}^{ \pm}
\end{aligned}
$$

subject to:

$$
\begin{aligned}
& \sum_{k=1}^{k^{\prime}} L_{k} D F^{ \pm}\left(\sum_{j=1}^{5} X_{1 j k}^{ \pm}+\sum_{r=1}^{6} X_{1 r k}^{ \pm}\right. \\
& \left.\quad+F E_{1}^{ \pm} \sum_{j=1}^{5} X_{2 j k}^{ \pm}+F E_{2}^{ \pm} \sum_{r=1}^{6} X_{2 r k}^{ \pm}\right) \leq T L C^{ \pm} \\
& \quad+\sum_{k=1}^{k^{\prime}} E L C_{k}^{ \pm}, k^{\prime} \\
& =1,2,3
\end{aligned}
$$


Table 2 Shipping cost for waste to facilities

\begin{tabular}{|c|c|c|c|}
\hline & $k=1$ & $k=2$ & $k=3$ \\
\hline \multicolumn{4}{|c|}{ Waste transport cost (to landfill) $(\$ / \mathrm{t})$} \\
\hline D1 & {$[8.44-0.0073 x, 10.34-0.0090 x]$} & {$[8.87-0.0076 x, 10.86-0.0093 x]$} & {$[9.57-0.0082 x, 11.73-0.0100 x]$} \\
\hline D2 & {$[6.74-0.0059 x, 9.41-0.0082 x]$} & {$[7.07-0.0061 x, 9.88-0.0085 x]$} & {$[7.64-0.0065 x, 10.67-0.0091 x]$} \\
\hline D3 & {$[5.60-0.0049 x, 8.40-0.0073 x]$} & {$[5.88-0.0051 x, 8.82-0.0076 x]$} & {$[6.35-0.0054 x, 9.52-0.0081 x]$} \\
\hline D4 & {$[7.30-0.0063 x, 9.59-0.0083 x]$} & {$[7.67-0.0066 x, 10.07-0.0087 x]$} & {$[8.28-0.0071 x, 10.88-0.0093 x]$} \\
\hline D5 & {$[0.98-0.0009 x, 6.74-0.0058 x]$} & {$[1.03-0.0009 x, 7.07-0.0061 x]$} & {$[1.11-0.0009 x, 7.64-0.0065 x]$} \\
\hline BJ & {$[3.26-0.0028 x, 3.75-0.0032 x]$} & {$[3.42-0.0029 x, 3.93-0.0034 x]$} & {$[3.69-0.0031 x, 4.25-0.0036 x]$} \\
\hline NG & {$[2.88-0.0025 x, 3.31-0.0029 x]$} & {$[3.02-0.0026 x, 3.47-0.0029 x]$} & {$[3.26-0.0028 x, 3.75-0.0032 x]$} \\
\hline CJ & {$[3.45-0.0030 x, 3.98-0.0034 x]$} & {$[3.62-0.0031 x, 4.18-0.0036 x]$} & {$[3.91-0.0033 x, 4.51-0.0038 x]$} \\
\hline XM & {$[2.51-0.0022 x, 2.88-0.0025 x]$} & {$[2.64-0.0022 x, 3.03-0.0026 x]$} & {$[2.85-0.0024 x, 3.27-0.0028 x]$} \\
\hline HG & {$[2.49-0.0022 x, 2.87-0.0025 x]$} & {$[2.62-0.0030 x, 3.01-0.0026 x]$} & {$[2.82-0.0024 x, 3.25-0.0028 x]$} \\
\hline $\mathrm{NH}$ & {$[3.37-0.0029 x, 3.88-0.0034 x]$} & {$[3.54-0.0030 x, 4.08-0.0035 x]$} & {$[3.83-0.0033 x, 4.40-0.0037 x]$} \\
\hline \multicolumn{4}{|c|}{ Waste transport cost (to incinerator) $(\$ / \mathrm{t})$} \\
\hline D1 & {$[3.27-0.0028 x, 5.77-0.0050 x]$} & {$[3.43-0.0029 x, 6.06-0.0052 x]$} & {$[3.71-0.0032 x, 6.54-0.0056 x]$} \\
\hline D2 & {$[4.17-0.0036 x, 6.26-0.0054 x]$} & {$[4.38-0.0038 x, 6.57-0.0056 x]$} & {$[4.73-0.0040 x, 7.10-0.0060 x]$} \\
\hline D3 & {$[3.45-0.0030 x, 6.66-0.0058 x]$} & {$[3.62-0.0031 x, 6.99-0.0061 x]$} & {$[3.91-0.0033 x, 7.55-0.0064 x]$} \\
\hline D4 & {$[1.04-0.0009 x, 2.30-0.0020 x]$} & {$[1.09-0.0009 x, 2.42-0.0021 x]$} & {$[1.17-0.0010 x, 2.61-0.0022 x]$} \\
\hline D5 & {$[2.83-0.0025 x, 7.15-0.0062 x]$} & {$[2.97-0.0025 x, 7.51-0.0065 x]$} & {$[3.21-0.0027 x, 8.11-0.0069 x]$} \\
\hline BJ & {$[0.48-0.0004 x, 0.55-0.0005 x]$} & {$[0.50-0.0004 x, 0.57-0.0005 x]$} & {$[0.54-0.0005 x, 0.62-0.0005 x]$} \\
\hline NG & {$[0.78-0.0007 x, 0.89-0.0008 x]$} & {$[0.82-0.0007 x, 0.94-0.0008 x]$} & {$[0.88-0.0007 x, 1.02-0.0009 x]$} \\
\hline CJ & {$[1.92-0.0017 x, 2.21-0.0019 x]$} & {$[2.01-0.0017 x, 2.31-0.0020 x]$} & {$[2.17-0.0018 x, 2.50-0.0021 x]$} \\
\hline XM & {$[1.74-0.0015 x, 2.01-0.0017 x]$} & {$[1.83-0.0016 x, 2.10-0.0018 x]$} & {$[1.98-0.0017 x, 2.27-0.0019 x]$} \\
\hline HG & {$[1.35-0.0012 x, 1.55-0.0013 x]$} & {$[1.42-0.0012 x, 1.63-0.0014 x]$} & {$[1.53-0.0013 x, 1.76-0.0015 x]$} \\
\hline $\mathrm{NH}$ & {$[3.37-0.0029 x, 3.88-0.0034 x]$} & {$[3.54-0.0030 x, 4.08-0.0035 x]$} & {$[3.82-0.0033 x, 4.40-0.0037 x]$} \\
\hline
\end{tabular}

$$
\begin{aligned}
& \sum_{j=1}^{5} X_{1 j k}^{ \pm}+\sum_{r=1}^{6} X_{1 r k}^{ \pm}+\sum_{j=1}^{5} F E_{1}^{ \pm} X_{2 j k}^{ \pm} \\
& +\sum_{r=1}^{6} F E_{2}^{ \pm} X_{2 r k}^{ \pm} \leq D L C^{ \pm}
\end{aligned}
$$

$$
\begin{aligned}
(1 & \left.+\widetilde{\theta^{ \pm}}\right)\left(\sum_{j=1}^{5} X_{2 j k}^{ \pm}+\sum_{r=1}^{6} X_{2 r k}^{ \pm}\right) \leq \widetilde{I C}^{ \pm} \\
& +\sum_{k=1}^{k^{\prime}} E I C_{k}^{ \pm}, k^{\prime} \\
& =1,2,3
\end{aligned}
$$

$$
\begin{aligned}
& \sum_{j=1}^{5} X_{r j k}^{ \pm} \leq T C_{r}^{ \pm}+\sum_{k=1}^{k^{\prime}} E T C_{r k}^{ \pm}, \forall r ; k^{\prime}=1,2,3 \\
& \sum_{j=1}^{5} X_{r j k}^{ \pm}\left(1-\eta_{4}^{ \pm}\right)=\sum_{i=1}^{2} X_{i r k}^{ \pm}, \forall r, k
\end{aligned}
$$

$$
\begin{aligned}
& \sum_{i=1}^{2} X_{i j k}^{ \pm}+\sum_{r=1}^{6} X_{r j k}^{ \pm} \geq W G_{j k}^{ \pm}, \forall j, k \\
& 0 \leq \sum_{k=1}^{3} E L C_{k}^{ \pm} \leq M E L C \\
& 0 \leq E I C_{k}^{ \pm} \leq M E I C_{k}, \forall k \\
& 0 \leq E T C_{r k}^{ \pm} \leq M E T C_{k}, \forall r, k \\
& \sum_{r=1}^{6} E T C_{r k}^{ \pm} \leq T E T C_{k}, \forall k \\
& X_{i j k}^{ \pm}, X_{r j k}^{ \pm}, X_{i r k}^{ \pm} \geq 0, \forall i, j, r, k
\end{aligned}
$$

The detailed nomenclatures for the variables and parameters are provided in the Appendix. The objective is to minimize the sum of the expenses for collecting, shipping and disposing wastes as well as costs for expanding transfer stations, landfill and incinerator. The constraints define the interrelationships 
Table 3 Transportation cost for waste from district to transfer station $(\mathbf{\$} / \mathbf{t})$

\begin{tabular}{|c|c|c|c|}
\hline & $k=1$ & $k=2$ & $k=3$ \\
\hline D1-BJ & {$[3.49-0.0030 x, 5.38-0.0047 x]$} & {$[3.66-0.0032 x, 5.65-0.0049 x]$} & {$[3.96-0.0034 x, 6.10-0.0052 x]$} \\
\hline D2-BJ & {$[4.73-0.0041 x, 6.44-0.0056 x]$} & {$[4.97-0.0043 x, 6.76-0.0058 x]$} & {$[5.37-0.0046 x, 7.30-0.0062 x]$} \\
\hline D3-BJ & {$[3.39-0.0029 x, 5.67-0.0049 x]$} & {$[3.56-0.0031 x, 5.96-0.0051 x]$} & {$[3.84-0.0033 x, 6.43-0.0055 x]$} \\
\hline D4-BJ & {$[1.25-0.0019 x, 5.36-0.0047 x]$} & {$[1.31-0.0011 x, 3.06-0.0026 x]$} & {$[1.41-0.0012 x, 3.30-0.0028 x]$} \\
\hline D5-BJ & {$[2.24-0.0019 x, 5.36-0.0047 x]$} & {$[2.35-0.0020 x, 5.62-0.0048 x]$} & {$[2.54-0.0022 x, 6.08-0.0052 x]$} \\
\hline D1-NG & {$[1.74-0.0015 x, 4.42-0.0038 x]$} & {$[1.83-0.0016 x, 4.64-0.0040 x]$} & {$[2.00-0.0017 x, 5.01-0.0043 x]$} \\
\hline D2-NG & {$[1.50-0.0013 x, 4.29-0.0037 x]$} & {$[1.57-0.0013 x, 4.51-0.0039 x]$} & {$[1.70-0.0014 x, 4.87-0.0041 x]$} \\
\hline D3-NG & {$[1.25-0.0011 x, 4.24-0.0037 x]$} & {$[1.31-0.0011 x, 4.45-0.0038 x]$} & {$[1.41-0.0012 x, 4.80-0.0041 x]$} \\
\hline D4-NG & {$[0.50-0.0004 x, 2.05-0.0018 x]$} & {$[0.52-0.0004 x, 2.15-0.0018 x]$} & {$[0.57-0.0005 x, 2.32-0.0020 x]$} \\
\hline D5-NG & {$[1.49-0.0013 x, 5.35-0.0046 x]$} & {$[1.57-0.0013 x, 5.61-0.0048 x]$} & {$[1.70-0.0014 x, 6.06-0.0052 x]$} \\
\hline D1-CJ & {$[0.25-0.0002 x, 2.91-0.0025 x]$} & {$[0.26-0.0002 x, 3.06-0.0026 x]$} & {$[0.28-0.0002 x, 3.30-0.0028 x]$} \\
\hline D2-CJ & {$[0.50-0.0004 x, 3.22-0.0028 x]$} & {$[0.52-0.0004 x, 3.38-0.0029 x]$} & {$[0.57-0.0005 x, 3.65-0.0031 x]$} \\
\hline D3-CJ & {$[2.24-0.0019 x, 3.37-0.0031 x]$} & {$[2.35-0.0020 x, 3.54-0.0030 x]$} & {$[2.54-0.0022 x, 3.83-0.0032 x]$} \\
\hline D4-CJ & {$[1.74-0.0015 x, 3.52-0.0031 x]$} & {$[1.83-0.0016 x, 3.69-0.0032 x]$} & {$[1.98-0.0017 x, 4.00-0.0034 x]$} \\
\hline D5-CJ & {$[2.99-0.0026 x, 6.14-0.0053 x]$} & {$[3.14-0.0027 x, 6.45-0.0055 x]$} & {$[3.39-0.0029 x, 6.97-0.0059 x]$} \\
\hline D1-XM & {$[2.99-0.0026 x, 3.22-0.0028 x]$} & {$[3.14-0.0027 x, 3.38-0.0029 x]$} & {$[3.39-0.0029 x, 3.65-0.0031 x]$} \\
\hline D2-XM & {$[1.74-0.0015 x, 2.91-0.0025 x]$} & {$[1.83-0.0016 x, 3.06-0.0026 x]$} & {$[1.98-0.0017 x, 3.30-0.0028 x]$} \\
\hline D3-XM & {$[0.54-0.0004 x, 2.45-0.0021 x]$} & {$[0.56-0.0005 x, 2.58-0.0022 x]$} & {$[0.61-0.0005 x, 2.78-0.0024 x]$} \\
\hline D4-XM & {$[1.50-0.0015 x, 5.65-0.0049 x]$} & {$[1.57-0.0013 x, 2.74-0.0024 x]$} & {$[1.70-0.0014 x, 2.96-0.0025 x]$} \\
\hline D5-XM & {$[1.74-0.0015 x, 5.65-0.0049 x]$} & {$[1.83-0.0016 x, 5.94-0.0051 x]$} & {$[1.98-0.0017 x, 6.41-0.0055 x]$} \\
\hline $\mathrm{D} 1-\mathrm{HG}$ & {$[4.99-0.0043 x, 5.98-0.0052 x]$} & {$[5.24-0.0045 x, 6.28-0.0054 x]$} & {$[5.66-0.0048 x, 6.78-0.0058 x]$} \\
\hline $\mathrm{D} 2-\mathrm{HG}$ & {$[2.51-0.0022 x, 3.36-0.0029 x]$} & {$[2.64-0.0023 x, 3.53-0.0030 x]$} & {$[2.85-0.0024 x, 3.81-0.0032 x]$} \\
\hline D3-HG & {$[1.01-0.0009 x, 3.02-0.0026 x]$} & {$[1.06-0.0009 x, 3.17-0.0027 x]$} & {$[1.14-0.0010 x, 3.42-0.0029 x]$} \\
\hline D4-HG & {$[1.26-0.0011 x, 2.91-0.0025 x]$} & {$[1.33-0.0011 x, 3.06-0.0026 x]$} & {$[1.44-0.0012 x, 3.30-0.0028 x]$} \\
\hline D5-HG & {$[0.58-0.0005 x, 2.15-0.0019 x]$} & {$[0.61-0.0005 x, 2.25-0.0019 x]$} & {$[0.66-0.0006 x, 2.43-0.0021 x]$} \\
\hline $\mathrm{D} 1-\mathrm{NH}$ & {$[4.73-0.0041 x, 5.37-0.0047 x]$} & {$[4.97-0.0043 x, 5.64-0.0049 x]$} & {$[5.37-0.0048 x, 6.09-0.0052 x]$} \\
\hline D2-NH & {$[1.75-0.0015 x, 3.35-0.0029 x]$} & {$[1.84-0.0016 x, 3.52-0.0030 x]$} & {$[1.99-0.0017 x, 3.80-0.0032 x]$} \\
\hline D3-NH & {$[0.53-0.0004 x, 3.22-0.0029 x]$} & {$[0.55-0.0005 x, 3.38-0.0029 x]$} & {$[0.60-0.0005 x, 3.65-0.0031 x]$} \\
\hline D4-NH & {$[5.31-0.0046 x, 6.46-0.0056 x]$} & {$[5.57-0.0048 x, 6.78-0.0058 x]$} & {$[6.02-0.0051 x, 7.33-0.0062 x]$} \\
\hline D5-NH & {$[1.74-0.0015 x, 5.79-0.0050 x]$} & {$[1.83-0.0016 x, 6.08-0.0052 x]$} & {$[1.98-0.0017 x, 6.56-0.0056 x]$} \\
\hline
\end{tabular}

among the decision variables and the waste generation/management conditions. In detail, constraints (17 b) to $(17$ e) denote that the wastes disposed by each treatment facility (i.e. landfill, incinerator and transfer stations) must not exceed their existing and expanded capacities; constraint (17 f) means that the mass balance of waste flows at transfer stations, where the volume of wastes can be reduced and various useful wastes can be recycled; constraint (17 g) denotes that the waste flows disposed by the wastemanagement facilities must be over the total waste generation amounts; constraints $(17 \mathrm{~h})$ to $(17 \mathrm{k})$ regulate the expansion scales for waste-management facilities; constraint (17 l) stipulates that the decision variables are non-negative.

\section{Result analysis}

Figure 4 presents the results for waste allocated from districts to different transfer stations to be pre-treated over the planning horizon. In detail, in period 1 , district 1 would use three transfer stations (i.e. namely NG, CJ and XM) to pre-treat and shift its wastes, while the amounts of wastes to NG, CJ and XM would be 44, [330.0, 343.2] and [216.0, 227.2] t/d (i.e. tonne/day), respectively; district 2 would ship $[765,813] \mathrm{t} / \mathrm{d}$ of waste to BJ; wastes from district 3 to XM, HG and $\mathrm{NH}$ would be $64,[256.0,277.2]$, and [310.0, 322.4] t/d, respectively; district 4 would employ BJ and NG to pre-treat its waste (i.e. 55 and [431 450] t/d of wastes, respectively); district 5 would only use HG to shift its wastes (i.e. $274 \mathrm{t} / \mathrm{d}$ ). The solutions of waste shipped to transfer stations in 

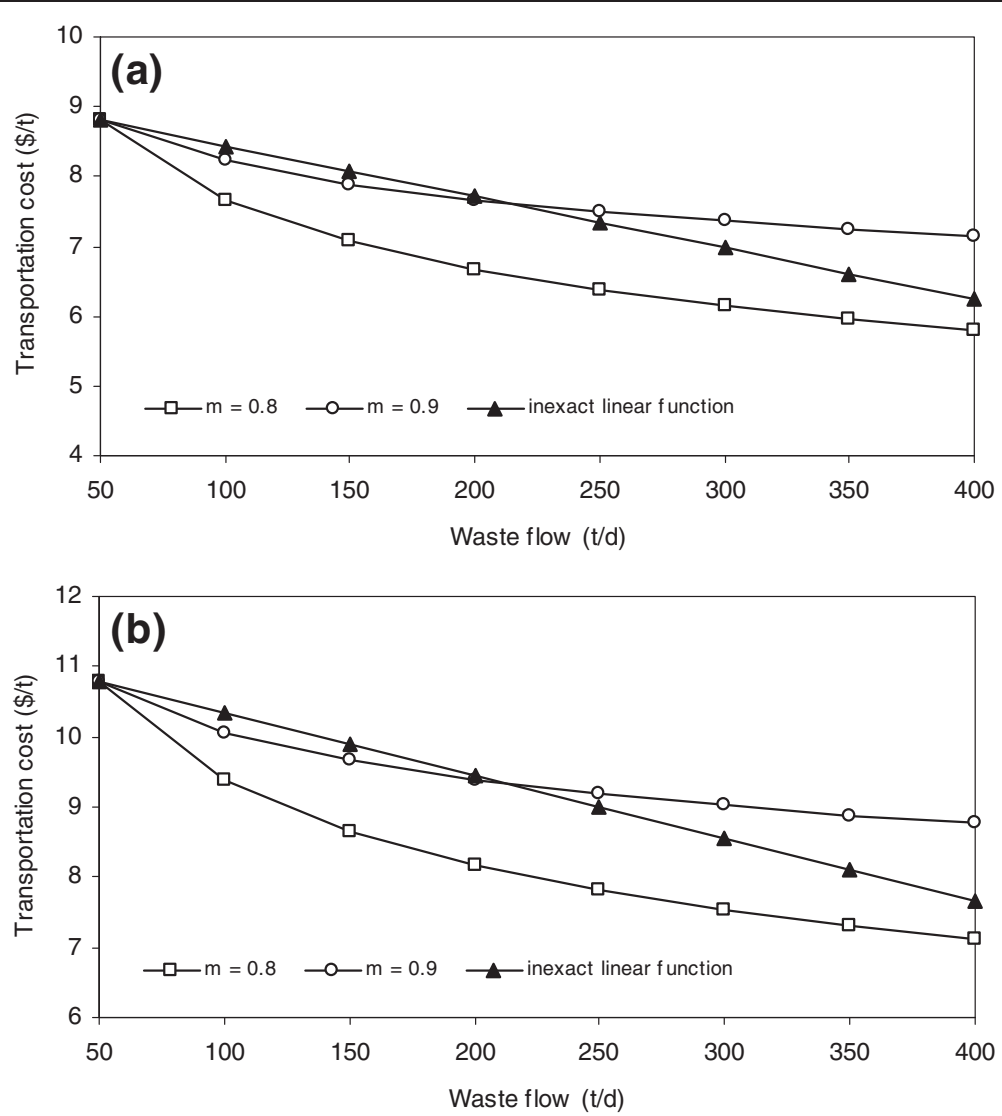

Figure 3 (a) Lower- and (b) upper-bound cost line.

periods 2 and 3 can be similarly interpreted based on the results as shown in Figure 4. In general, in period 1, the majority of wastes would be first transported to transfer stations to be pre-treated (i.e. $[2874,3268] \mathrm{t} / \mathrm{d}$ of wastes, occupying $[87.8,95.5] \%$ of total wastes generated in the five districts), while a small fraction of wastes would be directly hauled to landfill and incinerator; in periods 2 and 3, all wastes generated would be first shipped to transfer stations and then to landfill and/or incinerator. The transfer stations have many advantages in waste transportation and treatment such as (i) decreasing vehicle traffic going to and from landfill and

Table 4 Technical modeling inputs

\begin{tabular}{lc}
\hline Residue generation rate when waste is shipped from district to incinerator & {$[0.25,0.30]$} \\
Residue generation rate when waste is shipped from TR to incinerator & {$[0.12,0.15]$} \\
Density factor for waste disposed of at landfill $\left(\mathrm{m}^{3} / \mathrm{t}\right)$ & {$[1.47,1.82]$} \\
Volume of the existing landfill $\left(10^{3} \mathrm{~m}^{3}\right)$ & {$[76,80]$} \\
Daily landfill capacity (t/day) & {$[1950,2020]$} \\
Daily incinerator capacity (t/day) & {$[[440,470],[490,520]]$} \\
Safety coefficient for incinerator & {$[[0.09,0.13],[0.17,0.21]]$} \\
Electricity-generation rate when waste is shipped from district to incinerator (KWh/t) & {$[280,300]$} \\
Electricity-generation rate when waste is shipped from TR to incinerator (KWh/t) & {$[370,400]$} \\
Material recycling rate at TR & {$[0.16,0.20]$} \\
Mass loss rate at TR & {$[0.22,0.25]$} \\
Maximum expansion capacity for landfill $\left(10^{6} \mathrm{~m}^{3}\right)$ & 18 \\
Maximum expansion capacity once time for incinerator (t/day) & 250 \\
Maximum expansion capacity once time for transfer station (t/day) & 600
\end{tabular}




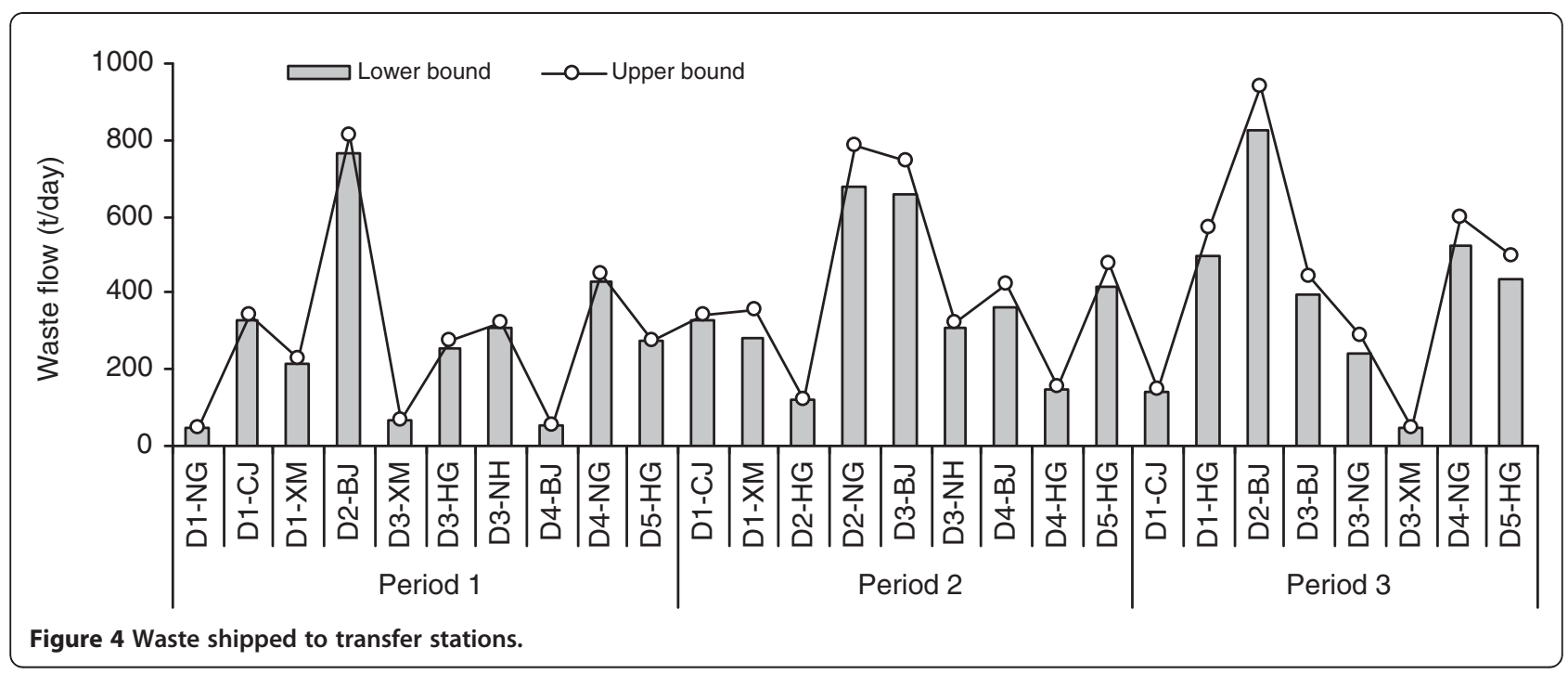

incinerator and thus reducing transportation cost, (ii) recycling various useful wastes, (iii) providing an inspection area where wastes can be viewed and unacceptable materials be removed, (iv) providing an effective control on dumping site at the landfill, (v) reducing the volume of wastes buried at the landfill, and (vi) raising the efficiency of incinerating wastes at the incinerator and reducing air-pollutant emissions. Besides, transfer stations are also more convenient for both MSW collectors and individual users since they are closer and easier to access than the landfill and incinerator sites.

Figure 5 shows the results of waste from transfer stations to landfill and incinerator over the planning span time. For example, in period 1, all wastes at the BJ, XM, HG and NH would be hauled to the landfill (i.e. [639.6, 651.0], 218.4, 413.4 and $241.8 \mathrm{t} / \mathrm{d}$, respectively); all
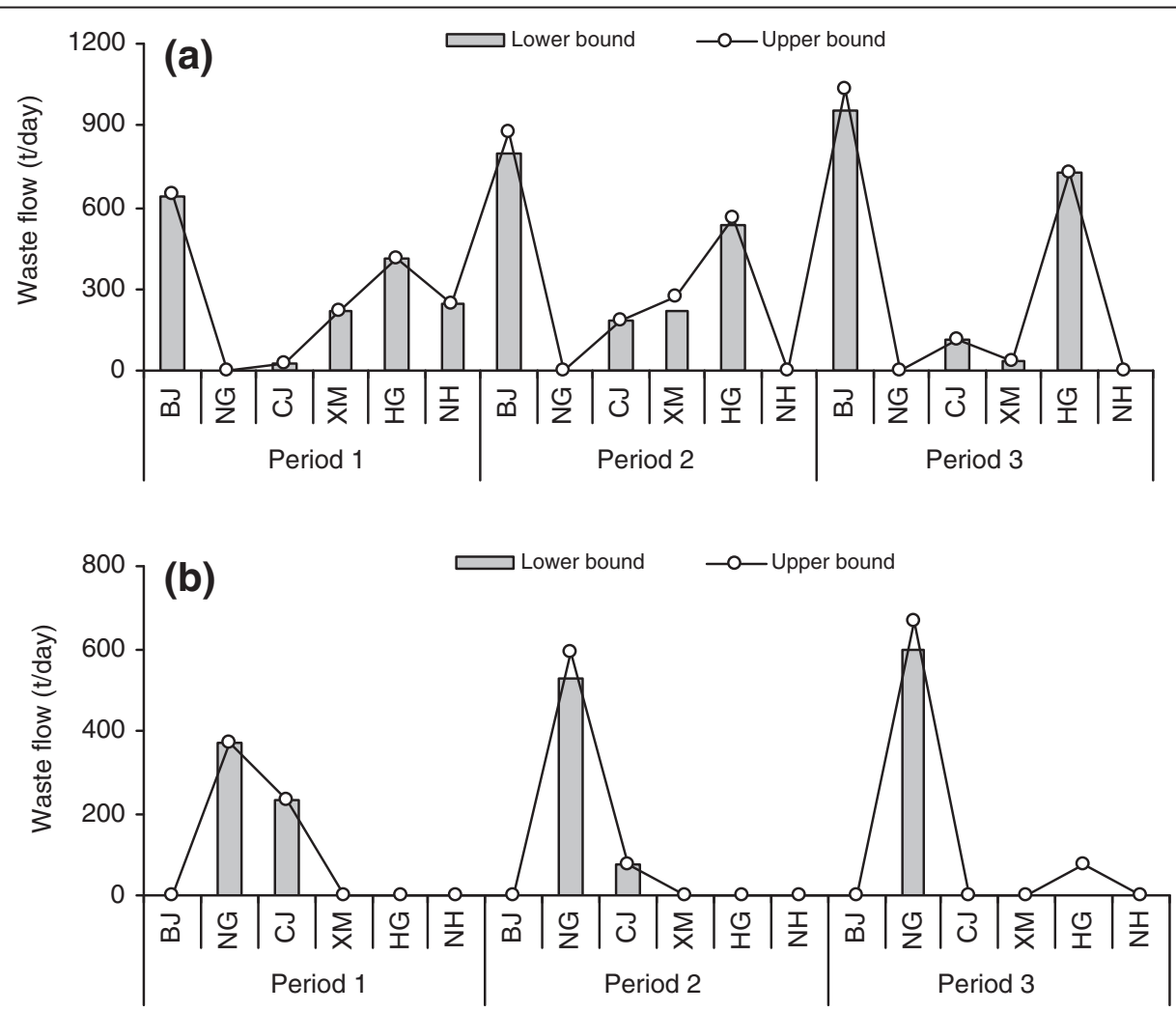

Figure 5 Waste from transfer stations to (a) landfill and (b) incinerator. 
wastes at NG would be shipped to the incinerator; wastes of CJ allocated to the landfill and incinerator would be 27.9 and $229.5 \mathrm{t} / \mathrm{d}$, respectively. In summary, landfill would be the main choice for disposal of the city's wastes; incinerator would help treat very small fraction of wastes. Figure 6 presents the amounts of wastes finally disposed at the landfill and incinerator. The amounts of wastes disposed of by the landfill would be [1670.1, 1903.5] $\mathrm{t} / \mathrm{d}$ in period $1,[1733.0,1889.3] \mathrm{t} / \mathrm{d}$ in period 2 , and $[1824.2,1909.3] \mathrm{t} / \mathrm{d}$ in period 3 ; the wastes treated by incinerator would be [600.0, 647.0], [600.0, 664.0] and [600.0, 738.2] t/d in periods 1, 2 and 3, respectively. Approximately [73.6, 74.4]\% of total wastes would be finally disposed of at the landfill over the planning horizon.

Since the city's MSW generation rates are increasing due to population expansion and economy development. Moreover, the available capacities of waste-management facilities may reduce with time periods (e.g. the cumulative capacity of landfill). This tendency could often result in insufficient capacities of waste-management facilities to meet the overall waste disposal of demand in future. The results indicate that capacity expansion for waste management facilities (including landfill, incinerator and transfer station) is required. The landfill would be expanded once in period 1, with an incremental volume of 18 million cubic meters. For transfer station and incinerator, there would be two expansion options corresponding to lowerand upper-bound objective function values (i.e. $f^{-}$and $f^{+}$), respectively. Figure 7 shows the optimal expansion scheme for the incinerator over the planning horizon. When the decision scheme tends toward $f^{-}$under advantageous system conditions, the incinerator would be expanded once in period 1 with an increment of $209.0 \mathrm{t} / \mathrm{d}$; conversely, when the scheme tends toward $f^{+}$under more demanding conditions, the incinerator would be expanded three times over the planning horizon, and the total expansion capacity is $364.4 \mathrm{t} / \mathrm{d}$ (i.e. with capacities of $263.2 \mathrm{t} / \mathrm{d}$ in period
$1,18.6 \mathrm{t} / \mathrm{d}$ in period 2 , and $82.7 \mathrm{t} / \mathrm{d}$ in period 3 ). Transfer stations would be expanded to satisfy increasing wastegeneration amount and waste pre-treatment requirement, as shown in Figure 8. For example, BJ would be expanded with capacities of [200.0, 288.0] t/d in period 1, [200.0, 214.2 ] $\mathrm{t} / \mathrm{d}$ in period 2 , and [200.0, 214.0] t/d in period 3. The capacities of BJ, NG, CJ, XM, HG and NH would reach to $[1180.0,1336.2],[739.2,915.3],[305.0,368.2]$, $[260.0,376.8],[900.0,1096.2]$ and $[280.0,352.4] \mathrm{t} / \mathrm{d}$, respectively. Consequently, the total transfer capacities would achieve [3664.2, 4445.1] t/d at the end of planning horizon (after capacity expansion), and lower and upper bounds respectively correspond to advantageous and demanding conditions.

\section{Discussion and conclusion}

A robust interval quadratic programming method has been developed through incorporating techniques of robust programming and interval quadratic programming within a general optimization framework. The developed method can not only tackle uncertainties expressed as interval values, fuzzy sets, and their combinations, but also deal with nonlinearities in the objective function such that economies-of-scale effects can be reflected. Furthermore, the uncertain decision space has been delimited through dimensional enlargement of the original fuzzy constraints, leading to enhanced robustness for the optimization process. Compared with the conventional quadratic programming methods, the developed method can address more uncertainties without unrealistic simplifications or information losses, such that the robustnesses of the optimization processes and solutions can be enhanced. The developed method has been applied to planning longterm municipal solid waste (MSW) management in the City of Changchun, China. The results have been generated, which are valuable for helping governmental officials more intuitive to know some basic situation under

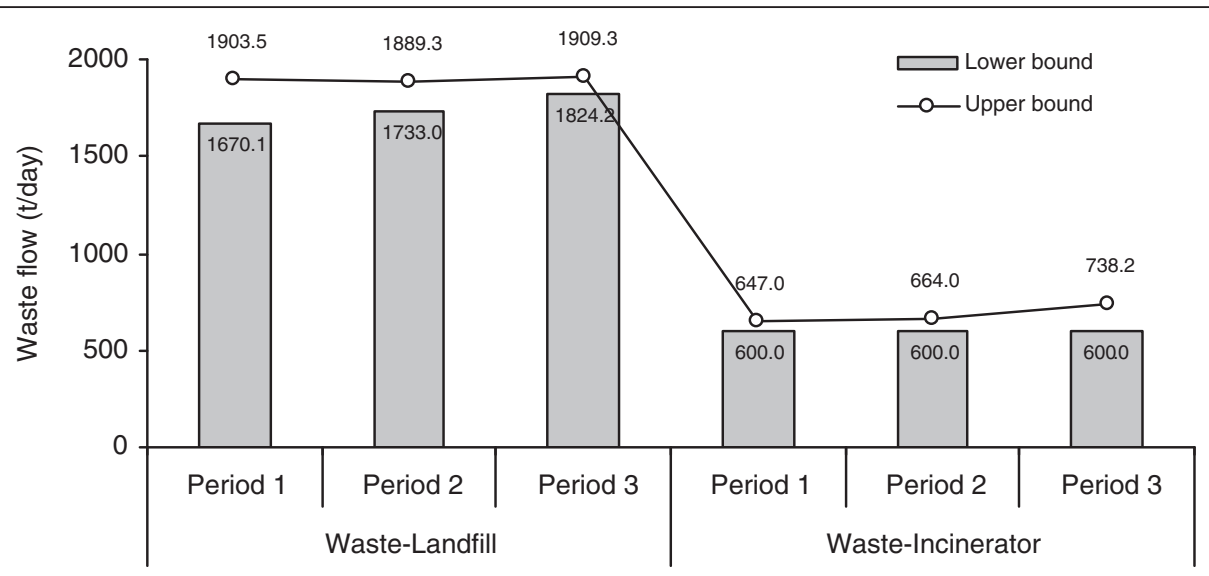

Figure 6 Waste disposed of at landfill and incinerator. 


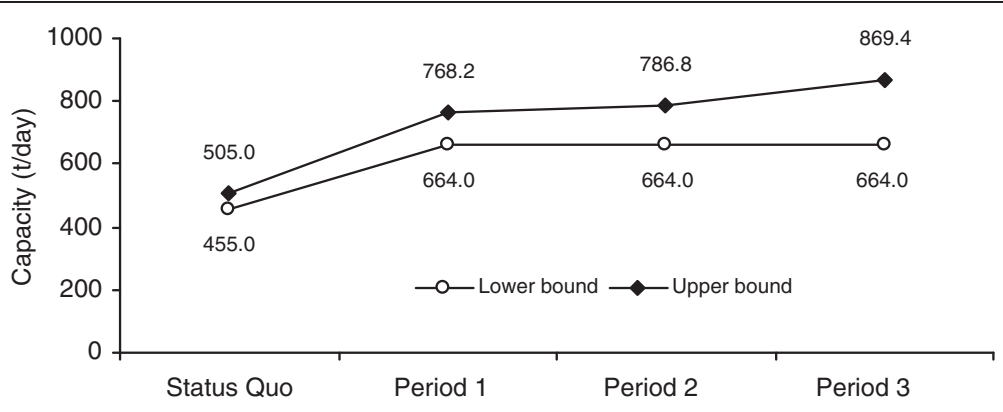

Figure 7 Capacity expansion scheme for incinerator.

complex uncertainties, such as optimal waste-flow allocation, waste-flow routing, facility-capacity expansion, and system cost. They can be used to further generate decisions for supporting long-term MSW management and planning activities in the city, and thus help managers to identify desired MSW policies in association with cost minimization under uncertainty.
The results indicate that, in the future 15 years, the city's majority of wastes would be disposed of at the landfill due to its relatively low operation cost and low capital for facility development/expansion. However, pollutant emissions from landfill site can take a number of forms: gaseous emissions of volatile organic compounds (VOCs), airborne particulate matter and leachate. For
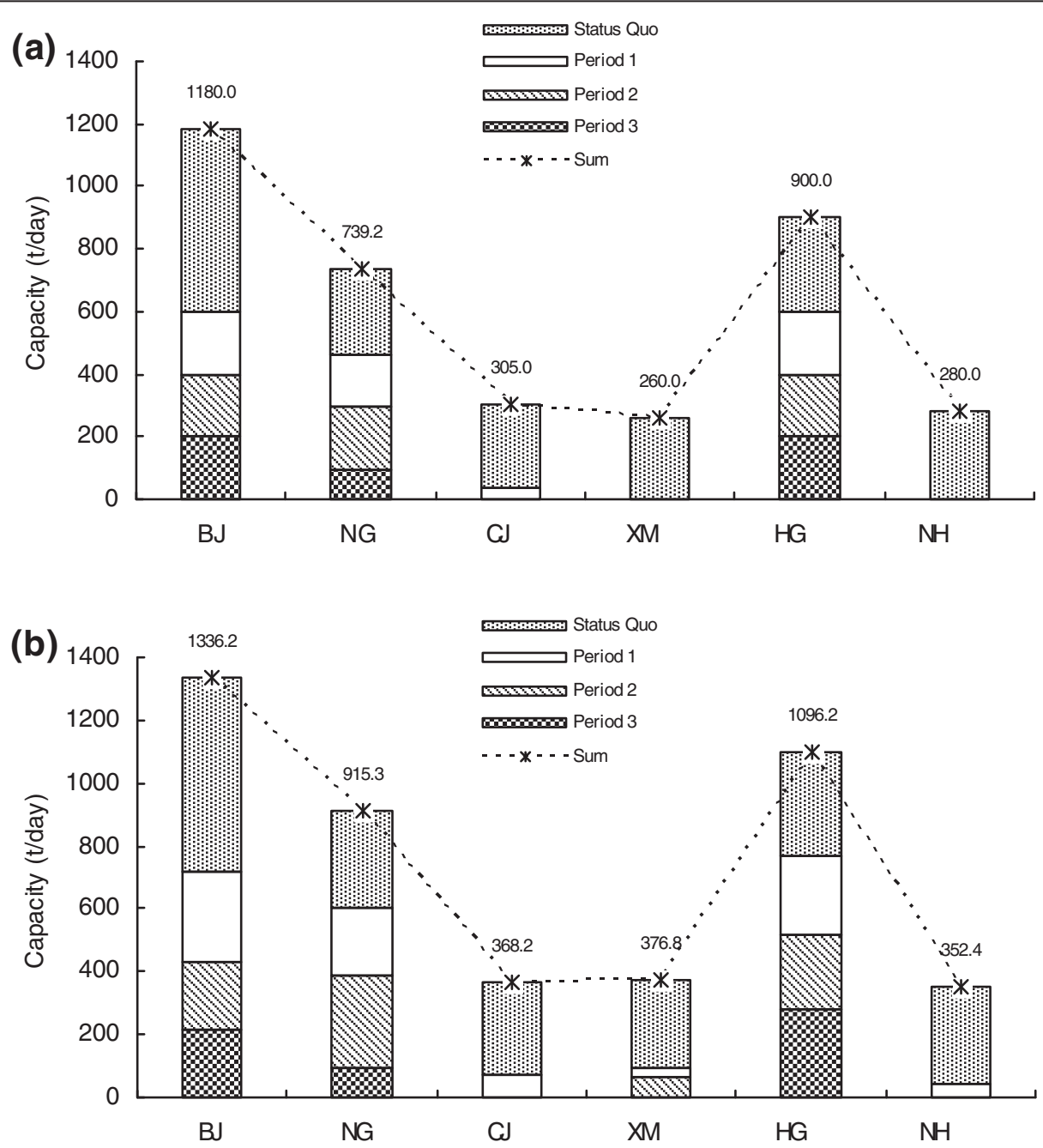

Figure 8 (a) Lower- and (b) upper-bound capacity-expansion schemes for transfer stations. 
example, surface water could be polluted by rainwater flowing through solid waste piles. Groundwater could be contaminated by leachate from landfill sites where solid wastes are disposed of. The polluted surface water and groundwater can further affect the drinking water safety; leachate containing hazardous materials can enter soil and further reside in the agricultural products that make our foods poisonous. Secondly, landfills are the first and/or second largest contribution of methane $\left(\mathrm{CH}_{4}\right)$ source (e.g. in 2006, the amount of $\mathrm{CH}_{4}$ released from landfills was $5985 \mathrm{Gg}$, occupying 23\% of total US anthropogenic methane emissions) (USEPA, 2007). Recently, there is an increasing concern for $\mathrm{CH}_{4}$, as a major greenhouse gas, while its global warming potential is about 23 on a 100-year time horizon (Mor et al. 2006; Chen et al. 2010). Thirdly, conflicts exist in the urban land resources due to the rapid population growth and swift economy development. Particularly, for the City of Changchun, the serious scarcity of land near urban centers leads to waste disposed of at landfill more and more noneconomic. Therefore, issues of land resource consumption, surface water/groundwater contamination, and greenhouse gas effect may imply higher environmental penalties than the savings obtained from waste buried.

The results also indicate that the city has to expand the incinerator to treat its more and more MSW over the planning horizon. Waste incineration can also generate considerable pollutant emissions (e.g. acid gases, metals and various organic compounds) that can present potential human health hazards. Incinerator emissions are complex and depend on the type of waste, the design of the incinerator, combustion conditions, and pollution control equipment. A number of pollutants (e.g. acid gases, metals and various organic compounds, including dioxins) are associated with health hazards and have thus raised serious concerns in the city. Therefore, research efforts focused on vulnerability analysis and risk assessment of human health and ambient environment for the city's incinerator are desired. Evaluation of the risk effects of air pollution on human health requires a series of assessment activities such as emission and dispersion of pollutants in the atmosphere, exposure of humans to pollutants, and adverse effects of the pollutants on human health; this will be of challenge for many waste managers. In addition, utilization of source-separated collection is one of the key steps in the city's future MSW management. Source-separated collection begins at the sources of MSW and involves the whole process of collection, transportation, disposal and recycling, which enables waste minimization, resource utilization, and hazardous waste disposal of. This also requires the local government to establish standards and regulations for the source separated collection.

\section{Appendix}

\section{Nomenclatures}

I type of waste disposal facility, where $\mathrm{i}=1$ for landfill, and $\mathrm{i}=2$ for INCINERATOR

$j$ name of district, and $j=1,2,3,4,5$

$r$ name of district, and $r=1,2,3,4,5,6$

$k$ planning period, and $k=1,2,3$

$L_{k}$ length of period $\mathrm{k}$ (day)

$\alpha_{i j k}^{ \pm}$slope of transportation cost curve for waste from district $\mathrm{j}$ to facility $\mathrm{i}$ during period $\mathrm{k}$

$\alpha_{r j k}^{ \pm}$slope of transportation cost curve for waste from district $j$ to transfer station $r$ in period $k$

$\beta_{r j k}^{ \pm} \quad$ Y-intersect of transportation cost curve for waste from district $j$ to transfer station $r$ in period $k$

$\alpha_{r j k}^{ \pm}$slope of transportation cost curve for waste from transfer station $r$ to facility $i$ in period $k$

$\beta_{r j k}^{ \pm}$Y-intersect of transportation cost curve for waste from transfer station $r$ to facility $i$ in period $k$

$\alpha_{2 k}^{ \pm}$slope of transportation cost curve for residue from INCINERATOR to landfill in period $\mathrm{k}$

$\beta_{2 k}^{ \pm} \quad$ Y-intersect of transportation cost curve for residue

$\sim$ from INCINERATOR to landfill in period $\mathrm{k}$

$\theta^{ \pm}$Safety coefficient of INCINERATOR

$D F^{ \pm}$Density factor for waste from district to landfill $\left(\mathrm{m}^{3} / \mathrm{t}\right)$

$F E_{1}^{ \pm}$Residue rate when waste is shipped from district to INCINERATOR (\% of incoming waste)

$F E_{2}^{ \pm}$Residue rate when waste is shipped from transfer station to INCINERATOR (\% of incoming waste)

$D L C^{ \pm}$Daily capacity of disposing waste at the landfills (t/day)

$\sim C^{ \pm}$Capacity of the INCINERATOR (tonne/day)

$O P_{i k}^{ \pm}$Operating cost of waste disposal facility i during period $k(\$ / t)$

$O P_{r k}^{ \pm}$Operating cost of transfer station $r$ during period $\mathrm{k}$ $(\$ / t)$

$R E_{2 k}^{ \pm}$Revenue from sale electricity generated at INCINERATOR in period $\mathrm{k}\left(\$ / 10^{3} \mathrm{KWh}\right)$

$R E_{r k}^{ \pm}$Revenue from recycling waste at transfer station $\mathrm{r}$ in period $\mathrm{k}\left(\$ / 10^{3} \mathrm{KWh}\right)$

$T L C^{ \pm}$Volume of existing landfill $\left(\mathrm{m}^{3}\right)$

$T R_{i r k}^{ \pm}$Transportation cost for waste flow from transfer station $\mathrm{r}$ to facility $\mathrm{i}$ in period $\mathrm{k}(\$ / \mathrm{t})$

$\eta_{1}^{ \pm}$Electricity-generation rate when waste is shipped from district to INCINERATOR (KWh/t)

$\eta_{2}^{ \pm}$Electricity-generation rate when waste is shipped from TR to INCINERATOR (KWh/t)

$\eta_{3}^{ \pm}$Material recycling rate at the transfer station (\%)

$\eta_{4}^{ \pm}$Mass loss ratio at the transfer station (\%)

$V L C_{k}^{ \pm}$Variable cost for expanding landfill in period $\mathrm{k}$ $\left(\$ / \mathrm{m}^{3}\right)$

$V T C_{r k}^{ \pm}$Variable cost for expanding transfer station $\mathrm{r}$ in period $\mathrm{k}(\$ / \mathrm{t})$ 
$V I C_{k}^{ \pm}$Variable cost for expanding INCINERATOR in period $\mathrm{k}(\$ / \mathrm{t})$

$W G_{j k}^{ \pm}$Amount of waste generated in district $\mathrm{j}$ in period $\mathrm{k}$ ( $t /$ day)

$X_{i j k}^{ \pm}$Waste flow from district $j$ to landfill or INCINERATOR in period $k$ ( $t /$ day)

$X_{\text {jrk }}^{ \pm}$Waste flow from district $\mathrm{j}$ to transfer station $\mathrm{r}$ in period k (t/day)

$X_{\text {irk }}^{ \pm}$Waste flow from transfer station $\mathrm{r}$ to landfill or INCINERATOR in period $k$ ( $t /$ day)

$E L C^{ \pm}$Volume of landfill to be expanded $\left(\mathrm{m}^{3}\right)$

$E I C_{k}^{ \pm}$Capacity expanded for INCINERATOR in period $\mathrm{k}$ (t/day)

$E T C_{r k}^{ \pm}$Capacity expanded for transfer station $\mathrm{r}$ in period $k(t /$ day)

MELC Maximum volume of landfill is allowed to be expanded $\left(\mathrm{m}^{3}\right)$

$M E I C_{k}$ Maximum allowance of capacity expansion for INCINERATOR in period $\mathrm{k}(\mathrm{t} /$ day)

$M E T C_{k}$ Maximum allowance of capacity expansion for each transfer station in period $\mathrm{k}$ ( $\mathrm{t} /$ day)

$T_{E T C}$ Maximum allowance of capacity expansion for total transfer stations in period $\mathrm{k}(\mathrm{t} /$ day)

\section{Competing interests}

The author declares that they have no competing interests.

\section{Authors' contributions}

YL developed a robust interval quadratic programming method and applied it to planning municipal solid waste management in the City of Changchun. $\mathrm{GH}$ participated in the method development and performed the result analysis. Both authors read and approved the final manuscript.

\section{Acknowledgements}

This Research was supported by the Natural Sciences Foundation of Beijing (8122038), the Program for Changjiang Scholars and Innovative Research Team in University (IRT1127), and the Program for New Century Excellent Talents in University (NCET-10-0376). The authors are grateful to the editors and the anonymous reviewers for their insightful comments and suggestions.

\section{Author details}

'MOE Key Laboratory of Regional Energy Systems Optimization, Resources and Environmental Research Academy, North China Electric Power University, Beijing 102206, China. ${ }^{2}$ MOE Key Laboratory of Regional Energy Systems Optimization, Resources and Environmental Research Academy, North China Electric Power University, Beijing 102206, China

Received: 30 March 2012 Accepted: 27 June 2012

Published: 1 September 2012

\section{References}

Baetz BW (1990) Optimization/simulation modeling for waste management capacity planning. Journal of Urban Planning and Development (ASCE) 116(2):59-79

Ben-Tal A, Nemirovski A (2002) Robust optimization - methodology and applications. Mathematic Program Search B 92:453-480

Cao MF, Huang GH (2011) Scenario-based methods for interval linear programming problems. Journal of Environmental Informatics 17(2):65-74

Chang NB, Davila E (2007) Minimax regret optimization analysis for a regional solid waste management system. Waste Manag 27:820-832

Changchun Urban Planning Council (2004) Master plan of Changchun City (2005-2020). Changchun, China (in Chinese)
Chen MJ, Huang GH (2001) A derivative algorithm for inexact quadratic programapplication to environmental decision-making under uncertainty. European Journal of Operational Research 128:570-586

Chen WT, Li YP, Huang GH, Chen X, Li YF (2010) A two-stage inexact-stochastic programming model for planning carbon dioxide emission trading under uncertainty. Applied Energy 87:1033-1047

Dubois D, Prade H (1978) Operations on fuzzy number. International Journal of Systems Science 9:613-626

Dubois D, Prade H, Sabbadin R (2001) Decision-theoretic foundations of qualitative possibility theory. European Journal of Operational Research 128:459-478

El Hanandeh A, El-Zein A (2010) Life-cycle assessment of municipal solid waste management alternatives with consideration of uncertainty: SIWMS development and application. Waste Manag 30:902-911

Fan YR, Huang GH (2012) A robust two-step method for solving interval linear programming problems within an environmental management context. Journal of Environmental Informatics 19(1):1-12

Hillier FS, Lieberman GJ (1986) Introduction to operations research, 4th edn. Holden-Day, Oakland, CA

Huang GH, Chi GF, Li YP (2005a) Long-term planning of an integrated solid waste management system under uncertainty - I. Model development. Environmental Engineering Science 22(6):823-834

Huang GH, Chi GF, Li YP (2005b) Long-term planning of an integrated solid waste management system under uncertainty - II. A north American case study. Environmental Engineering Science 22(6):835-853

Inuiguchi M, Sakawa M (1998) Robust optimization under softness in a fuzzy linear programming problem. International Journal of Approximate Reasoning 18:21-34

Kollikkathara N, Feng H, Yu DL (2010) A system dynamic modeling approach for evaluating municipal solid waste generation, landfill capacity and related cost management issues. Waste Manag 30:2194-2203

Ko AS, Chang NB (2008) Optimal planning of co-firing alternative fuels with coal in a power plant by grey nonlinear mixed integer programming model. J Environ Manage 88:11-27

Kuhn HW, Tucker AW (1951) Nonlinear programming. In: Neyman J (ed) Proceedings of the Second Berkeley Symposium on Mathematical Statistics and Probability, University of California Press. Berkeley, CA, pp 481-492

Li YP, Huang GH (2006) Minimax regret analysis for municipal solid waste management: An interval-stochastic programming approach. J Air Waste Manag Assoc 56(7):931-944

Li YP, Huang GH, Nie XH, Nie SL (2008) A two-stage fuzzy robust integer programming approach for capacity planning of environmental management systems. European Journal of Operational Research 189:399-420

Li YP, Huang GH, Yang ZF, Nie SL (2009) 0-1 Piecewise linearization approach for inexact nonlinear programming - application to environmental management under uncertainty. Canadian Journal of Civil Engineering 36:1071-1084

Li YP, Huang GH, Sun W (2011) Management of uncertain information for environmental systems using a multistage fuzzy-stochastic programming model with soft constraints. Journal of Environmental Informatics 18(1):28-37

Luhandjula MK, Gupta MM (1996) On fuzzy stochastic optimization. Fuzzy Set Syst 81:47-55

Lund JR, Tchobanoglous G, Anex R, Lawver R (1994) Linear programming for analysis of material recovery facilities. Journal of Environmental Engineering (ASCE) 120(5):1082-1094

Masui T, Morita T, Kyogoku J (2000) Analysis of recycling activities using a multisectoral economic model with material flow. European Journal of Operational Research 122(2):405-415

Mor S, Ravindra K, De Visscher A, Dahiya RP, Chandra A (2006) Municipal solid waste characterization and its assessment for potential methane generation: A case study. Sci Total Environ 371:1-10

Su J, Huang GH, Xi BD, Li YP, Qin XS, Huo SL, Jiang YH (2009) A hybrid inexact optimization approach for solid waste management in the city of Foshan, China. J Environ Manage 91(2):389-402

Tai J, Zhang WQ, Che Y, Feng D (2011) Municipal solid waste source-separated collection in China: A comparative analysis. Waste Manag 31:1673-1682

Thuesen HG, Fabrycky WJ, Thuesen GJ (1977) Engineering Economy. PrenticeHall, Englewood Cliffs, New Jersey

USEPA (2007) Municipal Solid Waste in the United States: 2007 Facts and Figures., 
Wilson BG, Baetz BW (2001a) Modeling municipal solid waste collection systems using derived probability distributions I: Model development. Journal of Environmental Engineering (ASCE) 127(11):1031-1038

Wilson BG, Baetz BW (2001b) Modeling municipal solid waste collection systems using derived probability distributions II: Extensions and applications. Journal of Environmental Engineering (ASCE) 127(11):1039-1047

doi:10.1186/2193-2697-1-7

Cite this article as: $L i$ and Huang: Robust interval quadratic

programming and its application to waste management under

uncertainty. Environmental Systems Research 2012 1:7.

Submit your manuscript to a SpringerOpen ${ }^{\circ}$ journal and benefit from:

- Convenient online submission

- Rigorous peer review

- Immediate publication on acceptance

- Open access: articles freely available online

- High visibility within the field

- Retaining the copyright to your article

Submit your next manuscript at $\gg$ springeropen.com 